\title{
A strong convergence theorem for maximal monotone operators in Banach spaces with applications
}

\section{E. Chidume ${ }^{1}$, G. S. DE SOUZA ${ }^{2}$, O. M. Romanus ${ }^{1}$ and U. V. NnYABA ${ }^{1}$}

\begin{abstract}
.
An algorithm is constructed to approximate a zero of a maximal monotone operator in a uniformly convex and uniformly smooth real Banach space. The sequence of the algorithm is proved to converge strongly to a zero of the maximal monotone map. In the case where the Banach space is a real Hilbert space, our theorem complements the celebrated proximal point algorithm of Martinet and Rockafellar. Furthermore, our convergence theorem is applied to approximate a solution of a Hammerstein integral equation in our general setting. Finally, numerical experiments are presented to illustrate the convergence of our algorithm.
\end{abstract}

Acknowledgements. The authors appreciate the support of their institute and the African Development Bank (AfDB) for the Research Grant that enable this work to be carried out. The authors wish to thank the referees for their esteemed comments and suggestions.

\section{REFERENCES}

[1] Alber, Ya. and Ryazantseva, I., Nonlinear Ill Posed Problems of Monotone Type, Springer, London, UK, 2006

[2] Bauschke, H. H., Matoušková, E. and Reich, S., Projection and Proximal Point Methods: convergence results and counterexeamples, Nonlinear Anal., 56 (2004), 715-738

[3] Browder, F. E., Fixed point theory and nonlinear problems, Bull. Am. Math. Soc., 9 (1983), No. 1, 1-39

[4] Browder, F. E., Existence and perturbation theorems for nonlinear maximal monotone operators in Banach spaces, Bull. Amer. Math. Soc., 73 (1967), No. 3, 322-327

[5] Brezis, H. and Browder, F. E., Some new results about Hammerstein equations, Bull. Amer. Math. Soc., 80 (1974), 567-572

[6] Brezis, H. and Browder, F. E., Existence theorems for nonlinear integral equations of Hammerstein type, Bull. Amer. Math. Soc., 81 (1975), 73-78

[7] Brezis, H. and Browder, F. E., Nonlinear integral equations and systems of Hammerstein type, Advances in Math., 18 (1975), No. 2, 115-147

[8] Browder, F. E., Nonlinear mappings of nonexpansive and accretive type in Banach spaces, Bull. Amer. Math. Soc., 73 (1967), 875-882

[9] Browder, F. E., de Figueiredo, D. G. and Gupta, C. P., Maximal monotone operators and nonlinear integral equations of Hammerstein type, Bull. Amer. Math. Soc., 76 (1970), 700-705

[10] Browder, F. E. and Gupta, C. P., Monotone operators and nonlinear integral equations of Hammerstein type, Bull. Amer. Math. Soc., 75 (1969), 1347-1353

[11] Bruck, Jr., A strong convergent iterative solution of $0 \in U(x)$ for a maximal monotone operator $U$ in Hilbert space, J. Math. Anal. Appl., 48 (1974), 114-126

[12] Bruck, R. E. and Reich, S., Nonexpansive projections and resolvents of accretive operators in Banach spaces, Houston J. Math., 3 (1977), 459-470

[13] Bot, R. I. and Csetnek, E. R., A hybrid proximal-extragradient algorithm with inertial effects, Numer. Funct. Anal. Optim., 36 (2015), 951-963

Received: 04.08.2019; In revised form: 27.04.2020; Accepted: 22.05.2020 2010 Mathematics Subject Classification. 47H09, 47H10, 47J25 47J05, 47J20.

Key words and phrases. Fixed points, proximal point algorithm, monotone mapping, strong convergence.

Corresponding author: C. E. Chidume; cchidume@aust.edu.ng 
[14] Cydotchepanovich, R., Nonlinear Hammerstein equations and fixed points, Publications de l'Institut Mathematique, 35 (1984), 119-123

[15] Chidume, C. E., Geometric Properties of Banach spaces and Nonlinear Iterations, Springer Verlag Series: Lecture Notes in Mathematics, Vol. 1965 (2009), ISBN 978-1-84882-189-7

[16] Chidume, C. E., Uba, M. O., Uzochukwu, M. I., Otubo, E. E. and Idu, K. O., Strong convergence theorem for an iterative method for finding zeros of maximal monotone maps with applications convex minimization and variational inequality problems, Proc. Edinb. Math. Soc., (2) 62 (2019), No. 1, 241-257

[17] Chidume, C. E. and Bello, A. U., An iterative algorithm for Approximating solutions of Hammerstein equations with monotone maps in Banach spaces, Appl. Math. Comput, 313 (2017), 408-417

[18] Chidume, C. E. and Idu, K. O., Approximation of zeros of bounded maximal monotone mappings, solutions of Hammerstein integral equations and convex minimization problems, Fixed Point Theory Appl., (2016) 2016:97, DOI 10.1186/s13663-016-0582-8

[19] Chidume, C. E and Shehu, Y., Approximation of solutions of equations of Hammerstein type in Hilbert spaces Fixed Point Theory, 16 (2015), No. 1, 91-102

[20] Chidume, C. E and Shehu, Y., Iterative approximation of solutions of generalized equations of Hammerstein type Fixed Point Theory, 15 (2014), No. 2, 427-440

[21] Chidume, C. E. and Djitte, N., An iterative method for solving nonlinear integral equations of Hammerstein type, Appl. Math. Comput., 219 (2013), No. 10, 5613-5621

[22] Chidume, C. E and Shehu, Y., Iterative approximation of solution of equations of Hammerstein type in certain Banach spaces, Appl. Math. Comput., 219 (2013), 5657-5667

[23] Chidume, C. E., Nnakwe, M. O. and Adamu, A., A strong convergence theorem for generalized- $\Phi$-strongly monotone maps, with applications, Fixed Point Theory and Appl., (2019), https://doi.org/10.1186/s13663019-0660-9

[24] Chidume, C. E., Adamu, A. and Chinwendu, L. O., Approximation of solutions of Hammerstein equations with monotone mappings in real Banach spaces, Carpathian J. Math.., 35 (2019), No. 3, 305-316

[25] Chidume, C. E, and Shehu, Y., Strong convergence theorem for approximation of solutions of equations of Hammerstein type, Nonlinear Anal., 75 (2012), No. 14, 5664-5671

[26] Chidume, C. E. and Djitte, N., Convergence Theorems for Solutions of Hammerstein Equations with Accretive-Type Nonlinear Operators, PanAmer Math. J., 22 (2012), No. 2, 19-29

[27] Chidume, C. E. and Djitte, N., Approximation of Solutions of Nonlinear Integral Equations of Hammerstein Type, ISRN Math. Anal., Volume 2012, Article ID 169751, 12 pages doi:10.5402/2012/169751

[28] Chidume, C. E. and Ofoedu, E. U., Solution of nonlinear integral equations of Hammerstein type, Nonlinear Anal., 74 (2011), 4293-4299

[29] Chidume, C. E. and Djitte, N., Approximation of solutions of Hammerstein equations with bounded strongly accretive nonlinear operators, Nonlinear Anal., 70 (2009), No. 11, 4071-4078

[30] Chidume, C. E. and Djitte, N., Iterative approximation of solutions of nonlinear equations of Hammerstein type, Nonlinear Anal., 70(2009), No. 11, 4086-4092

[31] Chidume, C. E. and Zegeye, H., Approximation of solutions of nonlinear equations of Hammerstein-type in Hilbert space, Proc. Amer. Math. Soc., 133 (2005), No. 3, 851-858

[32] Chidume, C. E. and Zegeye, H., Iterative approximation of solutions of nonlinear equation of Hammerstein-type, Abstr. Appl. Anal., 6 (2003), 353-367

[33] Chidume, C. E. and Zegeye, H., Approximation of solutions of nonlinear equations of monotone and Hammersteintype, Appl. Anal., 82 (8) (2003), No. 8, 747-758

[34] Chidume, C. E., The iterative solution of the equation $f \in x+T x$ for a monotone operator $T$ in $L^{p}$ spaces, J. Math. Anal. Appl. 116 (1986), No. 2, 531-537

[35] Djitte, N. and Sene, M., An iterative algorithm for approximating solutions of Hammerstein integral equations, Numer. Funct. Anal. Optim., 34 (2013), No. 12, 1299-1316

[36] Djitte, N. and Sene, M., Iterative solution of nonlinear integral equations of Hammerstein type with Lipschitz and accretive operators, ISRN Appl. Math., (2012), Article ID 963802, 15 pages, DOI:5402/2012/963802

[37] de Figueiredo, D. G. and Gupta, C. P., On the variational method for the existence of solutions of nonlinear equations of Hammerstein type, Proceedings of the American Mathematical Society, 40 (1973), 470-476

[38] Güler, O., On the convergence of the proximal point algorithm for convex minimization, SIAM J. Control Optim., 29 (1991), 403-419

[39] Kačurovskii, R. I., On monotone operators and convex functionals, Uspekhi Mathematicheskikh Nauk, 15 (1960), No. 4, 213-215

[40] Kamimura, S. and Takahashi, W., Strong convergence of a proximal-type algorithm in a Banach space SIAM J. Optim., 13 (2002), No. 3, 938-945 
[41] Lehdili, N. and Moudafi, A., Combining the proximal algorithm and Tikhonov regularization, Optimization, 37 (1996), 239-252

[42] Matsushita, S. Y. and Xu, L., On convergence of the proximal point algorithm in Banach spaces, Proc. Amer. Math. Soc., 139 (2011), No. 11, 4087-4095

[43] Minty, G. J., Monotone Networks, Proc. Roy Soc. Lond., 257 (1960), 194-212

[44] Martinet, B., Régularisation ďinéquations variationnelles par approximations successives, Revue française ďnformatique et de Recherche Opérationnelle, 4 (1970), 154-158

[45] Minty, G. J., Monotone (nonlinear) operators in Hilbert space Duke Math. J. 29 (1962), No. 4, 341-346

[46] Mendy, J. T., Sene, M. and Djitte, N., Explicit algorithm for Hammerstein equations with bounded, hemicontinuous and monotone mappings,Minimax Theory Appl., 2 (2017), No. 2, 319-343

[47] Minjibir, M. S. and Mohammed, I., Iterative algorithms of solutions of Hammerstein integral inclusions, Appl. Math. Comput., 320 (2018), 389-399

[48] Pascali, D., and Sburian, S., Nonlinear mappings of monotone type, Editura Academia Bucureşti, Romania, 1978

[49] Ofoedu, E. U. and Onyi, C. E., New implicit and explicit approximation methods for solutions of integral equations of Hammerstein type, Appl. Math. Comput., 246 (2014), 628-637

[50] Reich, S., Constructive techniques for accretive and monotone operators. Applied non-linear analysis, Academic Press, New York, (1979), 335-345

[51] Reich, S., Extension problems for accretive sets in Banach spaces, J. Functional Anal., 26 (1977), 378-395

[52] Reich, S., Iterative methods for accretive sets in Banach Spaces, Academic Press, New York, 1978, 317-326

[53] Reich, S. and Sabach, S., Two strong convergence theorems for a proximal method in reflexive Banach spaces, Numer. Funct. Anal. Optim., 31 (2010), No. 1-3, 22-44

[54] Rockafellar, R. T., Monotone operators and the proximal point algorithm,SIAM J. Control Optim., 14 (1976), No. $5,877-898$

[55] Sow, T. M. and Djitte, N., Hammerstein equations involving monotone operators in classical Banach spaces: On Chidume's open problem, SpringerPlus, 2015

[56] Sow, T. M, Diop, C. and Djitte, N., Algorithm for Hammerstein equations with monotone mappings in certain Banach spaces , Creat. Math. Inform., 25 (2016), No. 1, 101-114

[57] Solodov, M. V. and Svaiter, B. F., Forcing strong convergence of proximal point iterations in a Hilber space, Math. Program., Ser. A., 87 (5000) 189-202

[58] Xu, H. K., A regularization method for the proximal point algorithm, J. Global Optim., 36 (2006), No. 1, 115-125

[59] Zarantonello, E. ., Solving functional equations by contractive averaging, Tech. Rep. 160, U. S. Army Math. Research Center, Madison, Wisconsin, 1960

[60] Zegeye, H., Iterative solution of nonlinear equations of Hammerstein type, JIPAM. J. Inequal. Pure Appl. Math., 4 (2003), No. 5, Article 92, 12 pp.

${ }^{1}$ African University OF SCIENCE AND TeChNOlogy, ABUja

KM 10 AIRPORT ROAD, FCT, GALADIMAWA, NIGERIA

Email address: cchidume@aust.edu.ng

Email address: rromanuseaust.edu.ng

Email address: nukamaka@aust.edu.ng

${ }^{2}$ Department of Mathematics and Statistics

AUBURN UNIVERSITY

AubuRn AL 336849-5310-USA

Email address: desougs@auburn. edu 